\title{
Doppler Tissue Imaging to Assess Systolic Function in Chagas' Disease
}

\author{
Márcio Vinícius Lins Barros, Antonio Luiz Pinho Ribeiro, Fernando Santana Machado, \\ Manoel Otávio da Costa Rocha
}

Belo Horizonte, MG - Brazil

Objective - To assess the usefulness of Doppler tissue imaging (DTI) for evaluating the systolic function of chagasic patients with and without electrocardiographic abnormalities, in comparision with echocardiographic study.

Methods - We studied 77 patients divided into 3 groups as follows: group 1 -control; group 2 -chagasic patients with normal electrocardiographic findings; and group 3 - chagasic patients with abnormal electrocardiographic findings. The following parameters were assessed: left ventricular dimensions and ejection fraction, left atrial dimensions and diastolic function on echocardiography. Systolic velocity and regional isovolumic contraction time (IVCTr) of the septal, anterior, lateral, posterior and inferior left ventricular walls were assessed on DTI.

Results - Left ventricular cavitary dimensions, ejection fraction and DTI systolic wave showed significant differences between groups 1 and 3 and between groups 2 and 3, which were not found between groups 1 and 2 . IVCTr allowed a statistically significant discrimination among the 3 groups.

Conclusion - DTI allowed discrimination among the different groups assessed, being superior to echocardiography in identifying early abnormalities of contractility, and, therefore, potentially useful for detecting incipient myocardial alterations in chagasic patients with normal electrocardiographic findings.

Key words: Chagas' disease, echocardiography, Doppler tissue imaging

Ecoar - Medicina Diagnóstica, Departamento de Clínica Médica and Curso de Pós-Graduação em Medicina Tropical of the Faculdade de Medicina of the UFMG Mailing address: Márcio Vinícius Lins Barros - Av. do Contorno, 6760 - 30110110 - Belo Horizonte, MG, Brazil - E-mail: ecoar@ecoar.com.br English version by Stela Maris C. e Gandour
Chagas' disease is caused by the Trypanosoma cruzi protozoa and is one of the major causes of death in several countries in Latin America ${ }^{1}$, therefore having a great socioeconomic impact. The heart is the most frequently and severely impaired organ in Chagas' disease, and its impairment may result in death due to arrhythmia, heart failure, or thromboembolic phenomena ${ }^{2}$. Ventricular function is the major predictor of morbidity and mortality in chronic Chagas' heart disease $^{3,4}$, and the early identification of myocardial damage may be important in the individualized approach of chagasic patients. Of the investigative methods, 12-lead electrocardiography has been extensively studied in Chagas' disease. Although the presence of a normal electrocardiogram is related to an excellent prognosis ${ }^{5}$, evidence of left ventricular contractile abnormalities ${ }^{6,7}$, diastolic dysfunction ${ }^{8}$, and even sudden death ${ }^{9}$ exists in patients with Chagas' disease with no electrocardiographic abnormalities.

Doppler tissue imaging is a diagnostic modality that has recently been incorporated into echocardiography. It allows the regional and quantitative analysis of cardiac muscular contraction and expansion ${ }^{10}$. Several studies have been published showing the potential of this technique in identifying the incipient myocardial changes in several diseases ${ }^{11-13}$. The objective of this study was to determine the usefulness of Doppler tissue imaging for detecting early contractile abnormalities in Chagas' disease, comparing it with electrocardiography and conventional echo-Doppler cardiography.

\section{Methods}

We carried out a cross-sectional study with prospective data collection from January 1998 to April 1999. During this period, 77 patients were selected and divided into 3 groups: group 1) control (17 patients); group 2) chagasic patients with normal electrocardiograms (32); and group 3) hagasic patients with abnormal electrocardiograms (28). All patients were selected from the Referral Center for Training on Infectious and Parasitic Diseases of the Federal University of Minas Gerais, after receiving an individual explana- 
tion about the objectives of the study and signing the formal written consent. The research protocol was assessed and approved by the committee on research ethics of the institution.

For recruitment, the patients initially underwent anamnesis, standardized physical examination, electrocardiography, chest X-ray, and laboratory tests (hemogram, creatinine, urea, fasting glycemia, potassium, sodium, TSH, and serological tests for T. cruzi infection). The chagasic patients were considered those who were serologically positive for $T$. cruzi according to at least 2 of the 3 following techniques: indirect immunofluorescence, indirect hemagglutination, and ELISA.

The exclusion criteria were as follows: systemic arterial hypertension, defined as blood pressure level measured during physical examination $>140 / 90 \mathrm{mmHg}$; history suggestive of coronary heart disease; a previous episode suggestive of rheumatic disease; diabetes mellitus or glucose intolerance, according to the definition of the National Diabetes Data Group; thyroid dysfunction, manifested as abnormal levels of thyroid-stimulating hormone (TSH) and of free thyroxin (T4); renal failure, defined as an increase in creatinine and urea levels; chronic obstructive pulmonary disease, based on suggestive clinical, radiological, and electrocardiographic data; fluid and electrolytic disorders, based on sodium and potassium measurements; significant anemia, defined as hemoglobin below $10 \mathrm{~g} / \mathrm{dL}$; alcoholism, defined as a mean weekly ethanol consumption of $420 \mathrm{~g}$; pregnancy; and impossibility to undergo the tests in the protocol.

All patients underwent echo-Doppler cardiography with color-flow mapping and Doppler tissue imaging with the ATL HDI 5000 device (Bothell, Washington, USA). The following echocardiographic parameters were obtained: left ventricular final diastolic and systolic dimensions; left atrial diameter; and ejection fraction obtained according to the Simpson method with the software included in the device. Pulsed Doppler of the transmitral flow (E and A waves, E/A ratio, and deceleration time - DT) and of the left ventricular outflow tract (isovolumic relaxation time - IVRT) was used to assess diastolic function. Doppler tissue imaging was obtained with the apical window in the apical 4-chamber view, apical 2-chamber view, and long apical view to assess the septal, lateral, inferior, anterior, and posterior walls, placing the sample volume of the Doppler cursor at the level of the basal, middle, and apical portions of the referred walls to determine the velocities of contraction. Peak systolic velocity was obtained, and the time of regional isovolumetric contractility (TRIVC) was estimated measuring the interval between the electrocardiographic $\mathrm{Q}$ wave and the beginning of the systolic wave.

The clinical data and those generated during the procedures were analyzed with version 6 of the Epiinfo and version 11 of the Minitab statistical packages for Windows. In all tests performed, alpha lower than 0.05 was considered an indicator of statistical significance. Whenever possible, the mathematical transformations necessary for the treatment of data with the parametric methods were performed. The means obtained were studied by using the analysis of variance (ANOVA) and the LSD Fisher test for comparing the means of the 3 groups. For nonparametric variables, the KruskalWallis test was used with comparison of the medians after the Bonferroni adjustment for multiple tests. The values obtained were described as mean \pm standard deviation or median and interquartile range (for nonnormally distributed variables). Because age differed in the groups, the analysis of covariance was performed to determine the significance of this variable in the parameters assessed. $\mathrm{A} \mathrm{p}<0.05$ was considered significant.

\section{Results}

The general clinical and echocardiographic data are shown in table I, where no statistically significant difference between the control group and that of chagasic patients with normal electrocardiograms can be observed in regard to the general parameters of systolic function. Although patients in group 2 were older, the analysis of covariance did not detect a statistically significant correlation with any variable studied in this sample.

The electrocardiographic abnormalities observed in group 2 were as follows: supraventricular or ventricular, or both, extrasystoles (21.4\%); complete right bundle-branch block (57.1\%); incomplete right bundle-branch block (3.6\%); left anterior hemiblock (57.1\%); left ventricular hypertrophy (3.57\%); nonspecific alterations in repolarization (14.3\%); low voltage (3.6\%); and electric inactivity $(7.1 \%)$.

Table II shows the parameters related to diastolic function determined with conventional Doppler. A significant difference was observed in the deceleration time between the control and chagasic groups, although no difference was observed between the chagasic patients with and without electrocardiographic alterations when the test for comparing the means and that variable was used.

The assessment of TRIC with Doppler tissue imaging allowed discrimination between the 3 groups in almost all seg-

\begin{tabular}{|c|c|c|c|c|c|c|c|}
\hline Variable & Group 1 & Group 2 & Group 3 & $\mathrm{P}$ & $1 \times 2$ & $1 \times 3$ & $2 \times 3$ \\
\hline Age & $35.8 \pm 10.6$ & $40.7 \pm 8.5$ & $43.9 \pm 11.1$ & 0.03 & $\mathrm{~S}$ & $\mathrm{~S}$ & NS \\
\hline $\mathrm{EF}(\%)^{*}$ & $65(63.2-67.8)$ & $62(60-65)$ & $57(44.5-63)$ & 0.0001 & NS & $\mathrm{S}$ & $\mathrm{S}$ \\
\hline $\operatorname{LVDD}(\mathrm{mm})$ & $47.6 \pm 4.4$ & $50.1 \pm 4.1$ & $54.4 \pm 6.9$ & 0.0001 & NS & $\mathrm{S}$ & $\mathrm{S}$ \\
\hline $\mathrm{LA}(\mathrm{mm})$ & $33.6 \pm 2.6$ & $33.7 \pm 2.3$ & $36.3 \pm 4.2$ & 0.003 & NS & $\mathrm{S}$ & $\mathrm{S}$ \\
\hline
\end{tabular}




\begin{tabular}{|c|c|c|c|c|}
\hline \multicolumn{5}{|c|}{$\begin{array}{l}\text { Table II - Indices of diastolic function on conventional echo-Doppler } \\
\text { cardiography in } 60 \text { chagasic patients with and without electrocar- } \\
\text { diographic abnormalities and } 17 \text { healthy individuals }\end{array}$} \\
\hline \multirow[b]{2}{*}{ Variable } & \multirow[b]{2}{*}{ Control } & \multicolumn{2}{|c|}{ Chagasic patients } & \multirow[b]{2}{*}{$\mathrm{P}$} \\
\hline & & Normal ECG & Abnormal ECG & \\
\hline $\mathrm{E}$ & $73.9 \pm 2.8$ & $72.3 \pm 2$ & $70.7 \pm 2.2$ & 0.68 \\
\hline A & $52 \pm 2.8$ & $49.6 \pm 1.9$ & $50.8 \pm 2.2$ & 0.77 \\
\hline $\mathrm{E} / \mathrm{A}$ & $1.5 \pm 0.1$ & $1.6 \pm 0.1$ & $1.5 \pm 0.1$ & 0.63 \\
\hline IVRT & $85.6 \pm 1.8$ & $90.8 \pm 1.3$ & $89.8 \pm 1.5$ & 0.07 \\
\hline DT & $169.8 \pm 5.1$ & $181.3 \pm 3.6$ & $189.3 \pm 4$ & 0.02 \\
\hline
\end{tabular}

ments assessed, especially along the inferior and posterior walls. Table III shows the data obtained at the basal portion of the different walls of the left ventricular myocardium.

Although the analysis of the systolic wave on Doppler tissue imaging enabled the discrimination of patients in groups 1 and 3 and in groups 2 and 3 (chagasic patients with and without electrocardiographic abnormalities), no statistically significant difference was observed between the control group and that of the chagasic patients without electrocardiographic abnormalities (tab. IV).

Figure 1 depicts the evaluation of the basal portion of the interventricular septum on Doppler tissue imaging with the values of systolic-wave velocity and TRIC.

\section{Discussion}

The analysis of ventricular function is an essential determining factor in the therapeutical and prognostic assessment of patients with Chagas' heart disease in its different forms. Of the methods available, echocardiography provides a noninvasive and innocuous morphological and func-

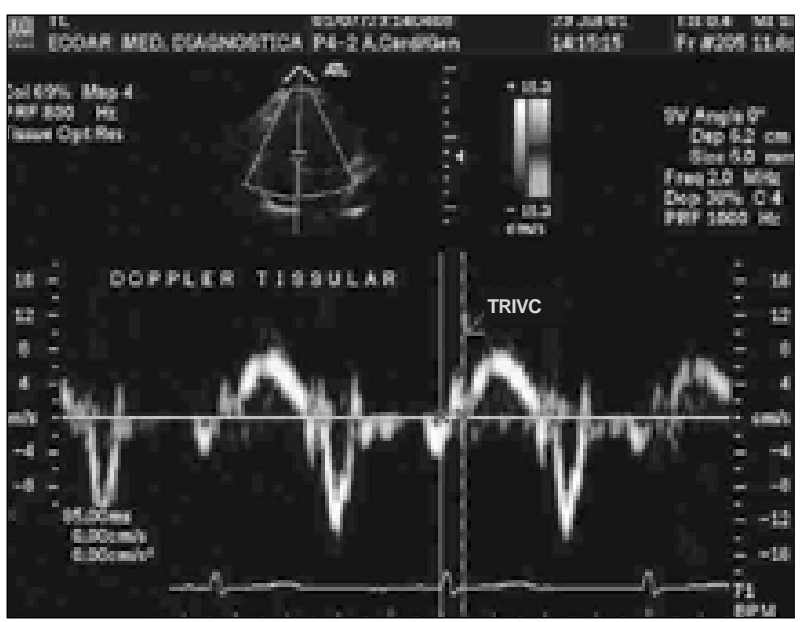

Fig. 1 - Pulsed Doppler tissue imaging of the basal segment of the ventricular septum. S- systolic wave; E- initial diastolic wave; A- late diastolic wave; TRIVC- time of regional isovolumetric contractility.

tional approach of the heart at relatively low costs. In addition, the analysis of ventricular function has a high diagnostic reliability, therefore being an important investigative tool to approach chagasic patients. The initial echocardiographic studies in Chagas' disease were performed with the M mode ${ }^{14}$. However, this method has several limitations for heart assessment. Because it only provides the visualization of the ventricular septal and posterior wall segments, it does not allow the analysis of the contractility of other segments, including the cardiac apex, which is a segment of essential importance in evaluating Chagas' heart disease, due to the peculiarities of the impairment of that region in Chagas' heart disease. In addition, the analysis of the right cavities, the quantitative evaluation of valvular heart diseases, the detection of intracavitary thrombi, and the determi-

\begin{tabular}{|l|ccc|c|}
\hline \multicolumn{2}{|c|}{ Table III - Time of regional isovolumetric contractility on Doppler tissue imaging of the basal segment of several left ventricular walls in the different } \\
groups studied
\end{tabular}

\begin{tabular}{|c|c|c|c|c|c|c|c|}
\hline & Group 1 & Group 2 & Group 3 & $\mathrm{P}$ & $1 \times 2$ & $1 \times 3$ & $2 \times 3$ \\
\hline Septum & $9.29 \pm 1.26$ & $8.54 \pm 1.06$ & $7.5 \pm 1.55$ & 0.0001 & NS & S & $\mathrm{S}$ \\
\hline Lateral & $10.76 \pm 2.1$ & $10.32 \pm 2.5$ & $8.35 \pm 2.51$ & 0.002 & NS & S & $\mathrm{S}$ \\
\hline Posterior & $10 \pm 1.96$ & $8.83 \pm 1.95$ & $7.1 \pm 2.64$ & 0.0001 & NS & S & $\mathrm{S}$ \\
\hline Inferior & $9.47 \pm 1.5$ & $8.58 \pm 1.8$ & $6.82 \pm 2.37$ & 0.0001 & NS & S & $\mathrm{S}$ \\
\hline Anterior & $10.3 \pm 1.49$ & $9.51 \pm 1.52$ & $7.96 \pm 2$ & 0.001 & NS & S & $\mathrm{S}$ \\
\hline
\end{tabular}


nation of the diastolic function and pulmonary arterial pressure, which are extremely important data in a general cardiac assessment, cannot be measured with this technique. The introduction of the 2-dimensional and Doppler techniques provided important additional information for the assessment of chagasic patients, allowing a more complete and noninvasive morphological and functional cardiac study ${ }^{15-17}$. However, the analysis of ventricular function with 2-dimensional echocardiography to evaluate wall motility or thickness, or both, and to determine the volumes and ejection fraction, which require the delineation of the muscle/cavity interface, renders the method a subjective character related to inter- and intraobserver variations, because the experience required in the subjective quantification of myocardial motility requires long-term experience with the method. The techniques allowing the quantitative analysis of myocardial contractile status have, therefore, great potential in the study of the cardiac function.

The studies of ventricular fiber architecture have revealed a complex disposition of the myocardial fibers, with the predominance of a circumferential orientation for the middle muscle layer and a longitudinal disposition of the muscle fibers at the subendocardial level ${ }^{18}$. The importance of the longitudinal contractility has been demonstrated in several echocardiographic studies, both for the analysis of the systolic function, and also for the assessment of ventricular relaxation ${ }^{19}$. Of the methods used, Doppler tissue imaging has a great potential for the study of longitudinal contractility. Unlike the study of flow dynamics at the level of the cardiac cavities, which are characterized by elevated velocities and low amplitude, Doppler tissue imaging uses a "filter" to eliminate the signal originating from the blood flow and to study the Doppler pattern at the level of the cardiac muscle, characteristically of high amplitude and low velocities. Therefore, we can analyze quantitatively the characteristics of myocardial wall motility throughout the cardiac cycle, which enables a more accurate analysis of myocardial performance. Several studies have been conducted to validate the method in several pathological cardiac conditions, including Chagas' disease ${ }^{20-23}$.

This study showed the usefulness of Doppler tissue imaging for evidencing alterations in the contractility of the longitudinal fibers of the left ventricular myocardium in Chagas' disease. The alterations on Doppler tissue imaging were present in both groups of chagasic patients, those with and without electrocardiographic abnormalities, showing early impairment in systolic function in these patients, even in the absence of electrocardiographic and echocardiographic abnormalities.

In the group studied, the alterations on Doppler tissue imaging related more to the isovolumetric contractility phase. This phase of the cardiac cycle relates to the excitation-contraction coupling and to the capacity of the muscular mass to develop, in a fraction of a second, strength enough to overcome the pressure exerted by the arterial vascular bed. For this to happen efficiently, harmony among the several components of the heart is required, not only the myocardial fibers, but also the components of the support and fibrous skeletal system, the interstitium, the excitationconducting system, the autonomic nervous system, and vascular integrity. Chagasic myocarditis causes disorders in all these components ${ }^{24}$, and even in the case of focal and less intense impairment, it may cause mild alterations in ventricular function, as already shown.

The results obtained allowed determining the presence of segmentary alterations relative to ventricular longitudinal contraction, reflecting heterogeneity in the muscular shortening of the different myocardial walls in Chagas' heart disease. Of the different segments assessed, the posterior and inferior walls showed the most significant alterations in the groups studied, reflecting the segmentary characteristic of the myocardial systolic impairment in chronic Chagas' heart disease.

The limitations of the use of Doppler tissue imaging in this study related to the difficulty in analyzing the velocities at the level of the cardiac apex, which is a region of special interest in assessing cardiac impairment in chagasic patients. This region is usually stationary in regard to the motility of the cardiac muscle layers, and, therefore, the criteria of abnormality on Doppler tissue imaging have little value as compared with those of the normal pattern. In addition, studies with pulsed Doppler require obtainment of several samples along the myocardial walls, which increases the duration of the examination. The values obtained on Doppler tissue imaging also relate to cardiac translation motility; however, the data obtained did not aim at providing absolute values of velocity of myocardial contraction and expansion, but at comparatively assessing the 3 groups.

In conclusion, for studying the systolic function of Chagas' heart disease, Doppler tissue imaging proved to be superior to electrocardiography and conventional echoDoppler cardiography in detecting incipient contractile abnormalities. This is because it shows regional alterations, allows the differentiation between normal patients and the chagasic ones with and without electrocardiographic alterations, and may be useful in the early detection of myocardial damage in those patients. Prospective studies of the longitudinal cohort type may confirm the efficacy of this method in evaluating the natural history of patients with myocardial alterations, thus far considered subclinical.

\section{References}

1. World Health Organization Expert Committee. Chagas' disease. In: World Organization Technical Report Series 697. Geneva: WHO, 1984: 50-5.

2. Rossi MA, Bestetti RB. The challenge of chagasic cardiomyopathy. The pathologic roles of autonomic abnormalities, autoimmune mechanisms and microvascular changes, and therapeutic implications. Cardiology 1995; 86: 1-7.
3. Bestetti RB, Muccillo G. Clinical course of Chagas' heart disease: a comparison with dilated cardiomyopathy. Int J Cardiol 1997; 25: 187-93.

4. Mady C, Cardoso RHA, Barreto ACP, Luz PL, Bellotti G, Pileggi F. Survival and predictors of survival in patients with congestive heart failure due to Chagas' cardiomyopathy. Circulation 1994; 90: 3098-102. 
5. Maquire JH, Hoff R, Sherlock I, et al. Cardiac morbidity and mortality due to Chagas' disease: prospective electrocardiographic study of a Brazilian community. Circulation 1987; 75: 1140-5.

6. Pazin-Filho A, Almeida Filho OC, Furuta MS, et al. Prognostic implications of minor segmental wall abnormalities in patients with Chagas' disease. J Am Coll Cardiol 1998; 31: 339C.

7. Ribeiro ALP, Rocha MOC, Barros MVL, Rodriques ARV, Machado FS. The QRS duration does not predict the left ventricular function in Chagas disease. Pacing Clin Electrophysiol 2000; 23: 2014-7.

8. Combellas I, Puigbo JJ, Acquatella H, Tortoledo F, Gomez JR. Echocardiography features of impaired left ventricular diastolic function in Chagas' heart disease. $\mathrm{Br}$ Heart J 1985; 53: 298-309.

9. Bestetti RB, Freitas OC, Muccilo G, Oliveira JS. Clinical and morphological characteristics associated with suden cardiac death in patients with Chagas' disease. Eur Heart J 1993; 14: 1610-4.

10. Izaaz K, Thompson A, Ethevenot G, Gloez GL, Brembilla B, Pernot C. Doppler echocardiography measurement of low velocity motion of the left ventricular posterior wall. Am J Cardiol 1989; 64: 66-75.

11. Garcia FMA, Azevedo J. Regional diastolic function in ischaemic heart disease using pulsed wave Doppler tissue imaging. Eur Heart J 1999; 20: 496-507.

12. Severino $\mathrm{S}$, Caso $\mathrm{P}$, Galderisi $\mathrm{M}$, et al. Use of pulsed Doppler tissue imaging to assess regional left ventricular diastolic dysfunction in hypertrophic cardiomyopathy. Am J Cardiol 1998; 82: 1394-8.

13. Barros MVL, Rocha MOC, Ribeiro ALP, Machado FS. Tissue Doppler imaging enabled the identification of diastolic dysfunction of pseudonormal pattern in Chagas' disease. J Am Soc Echocardiogr 2001; 14: 353-9.

14. Friedmann AA. Desempenho ventricular na doença de Chagas. Estudo ecocardiográfico em fase pré-clínica. Tese Livre-Docência. Faculdade de Medicina da USP. São Paulo, 1978: 61p.
15. OrtizJ, Barretto ACP, Matsumoto AY, et al. Alteração contrátil segmentarna forma indeterminada da doença de Chagas: estudo ecocardiográfico. Arq Bras Cardiol 1987; 49: 217-20.

16. Acquatella H, Schiller NB, Puigbo JJ, et al. M-mode and two-dimensional echocardiography in chronic Chages' heart disease: a clinical and pathologic study. Circulation 1980; 62: 787-99.

17. Bestetti RB, Dalbo CM, Freitas OC, Teno LA, Castilho OT, Oliveira JS. Noninvasive predictors of mortality for patients with Chagas' heart disease: a multivariate stepwise logistic regression study. Cardiology 1994; 84: 261-7.

18. Greenbaum RA, HO SY, Gibson DG, et al. Left ventricular fibre architecture in man. Br Heart J 1981; 45: 248-63.

19. Jones CJH, Raposo L, Gibson DG. Functional importance of the long axis dynamics of the human left ventricle. Br Heart J 1990; 63: 215-20.

20. Oki T, Tabata T, Yamada H, et al. Clinical application of pulsed Doppler tissue imaging for assessing abnormal left ventricular relaxation. Am J Cardiol 1997; 79: $921-8$

21. Garcia MJ, Rodriques L, Ares M, Griffin BP, Thomas JD, Klein AL. Differentiation of constrictive pericarditis from restrictive cardiomyopathy: assessment of left ventricular diastolic velocities in the longitudinal axis by Doppler tissue imaging. J Am Coll Cardiol 1996; 27: 108-14.

22. Garcia-Fernandez MA, Zamorano J, Azevedo J. Doppler Tissue Imaging in Ischemic Heart Disease. In: Doppler Tissue Imaging Echocardiography. Madrid: Mcgraw-Hill, 1998: 63-87.

23. Barros MVL, Ribeiro ALP, Rocha MOC, Machado FS. Doppler tissue imaging to evaluate early myocardium damage in patients with undetermined form of Chagas' disease and normal echocardiogram. Echocardiography 2001; 18: 131-6.

24. Bogliolo L. As causas anatômicas da insuficiência cardíaca na cardiopatia (miocardite) chagásica crônica, estudadas comparativamente com as causas anatômicas da insuficiência cardíaca noutras patologias (Parte 2). Arq Bras Cardiol 1976; 29: 479-83. 